\title{
SISTEMA DE BICICLETAS COMPARTILHADAS: UMA PESQUISA EXPLORATÓRIA SOBRE O POTENCIAL DESTE MERCADO NA CIDADE DE NOVA IGUACU-RJ
}

\author{
BICYCLE-SHARING SYSTEM: AN EXPLORATORY RESEARCH ON THE \\ POTENTIAL OF THIS MARKET IN THE CITY OF NOVA IGUAÇU-RJ
}

\author{
Andrey Santana Barbosa \\ Bacharel em Administração \\ Universidade Federal Rural do Rio de Janeiro - UFRRJ. \\ Nova Iguaçu, Rio de Janeiro - Brasil. \\ andrey.barbosa.0915@gmail.com \\ Janaina Nascimento Simões de Souza \\ Doutora \\ Universidade Federal Rural do Rio de Janeiro - UFRRJ. \\ Nova Iguaçu, Rio de Janeiro - Brasil. \\ jananss@yahoo.com.br
}

\begin{abstract}
Resumo: Os problemas de trânsito nas metrópoles brasileiras se tornaram, nas últimas décadas, cada vez mais intensos, gerando externalidades econômicas, sociais e ambientais. Esse cenário agravado acaba por engendrar pressões que incitam a necessidade de soluções por parte dos agentes públicos e privados, e uma das respostas é a criação da Política Nacional de Mobilidade Urbana, que define os transportes ativos, entre eles a bicicleta, como prioridade. Este trabalho teve o objetivo geral de verificar o potencial de mercado para a implementação de um sistema de bicicletas compartilhadas na cidade de Nova Iguaçu-RJ. Dessa forma, foi realizada uma pesquisa de mercado para análise qualitativa desta demanda latente entre os respondentes. O levantamento se deu por meio de pesquisa descritiva, com questionário eletrônico para coleta de dados primários. Foram levantadas 175 respostas, sendo 149 habilitadas para o estudo. Verificou-se que há o interesse, por parte da maioria $(62,42 \%)$, na implementação de um sistema de bicicletas compartilhadas na cidade de Nova Iguaçu-RJ. Foram também mapeados os principais pontos de preferência para estações do serviço de compartilhamento de bicicletas, assim como foi realizado o levantamento de preços para o serviço, que variou entre $\mathrm{R} \$ 5$ e $\mathrm{R} \$ 15$. Aponta-se para a necessidade de ampliação desta pesquisa em duas direções: identificação dos custos operacionais de implementação do sistema e verificação de políticas públicas relacionadas à promoção da mobilidade ativa.
\end{abstract}

Palavras-chave: Bicicletas compartilhadas. Potencial de mercado. Mobilidade urbana.

\begin{abstract}
Traffic problems in Brazilian metropolises have become increasingly intense in recent decades, generating economic, social and environmental externalities. This aggravated scenario ends up generating pressures that incite the need for solutions by public and private agents, and one of the answers is the creation of the National Policy of Urban Mobility, which defines active transportation, among them the bicycle, as a priority. This study had the general objective of verifying the market potential for the implementation of a bike sharing system in the city of Nova Iguaçu-RJ. Thus, a market research was conducted for qualitative analysis of this latent demand among the respondents. The survey was carried out through descriptive research, with an electronic questionnaire for primary data collection. A total of 175 responses were collected, 149 of which qualified for the study. It was verified that there is interest, on the part of the majority $(62.42 \%)$, in the implementation of a bike sharing system in the city of Nova Iguaçu-RJ. The main points of preference for bicycle sharing service stations were also mapped, as well as the prices for the service, which varied between $\mathrm{R} \$ 5$ and $\mathrm{R} \$ 15$. It is pointed out the need to expand this research in two directions: identification of the operational costs of implementing the system and verification of public policies related to the promotion of active mobility.
\end{abstract}

Keywords: Shared bicycles. Market potential. Urban mobility.

\section{Cite como}

American Psychological Association (APA)

Barbosa, A. S., \& Souza, J. N. S. (2021, jul./dez.). Sistema de bicicletas compartilhadas: uma pesquisa exploratória sobre o potencial deste mercado na cidade de Nova Iguaçu-RJ. Revista Inovação, Projetos e Tecnologias - IPTEC, São Paulo, 9(2), 148-167. https://doi.org/10.5585/iptec.v9i2.19001. 


\section{Introdução}

Há alguns anos, os problemas de mobilidade são mais frequentes no debate público. As evidências atestam condições preocupantes, como o alto índice de congestionamentos, perdas de produtividade por problemas de deslocamento, assim como a baixa qualidade de vida dos cidadãos por precisarem enfrentar horas no trânsito (Silva, 2013). As cidades brasileiras, de maneira geral, se mostram saturadas de automóveis e começam, lentamente, a tentar rever o processo e as políticas de mobilidade urbana. As intensificações negativas do cenário resultam em pressões que incitam a necessidade de soluções por parte dos agentes públicos, que, entre outras, respondem com a criação da Lei $\mathrm{n}^{\circ} .12 .587$ (Brasil, 2012), que institui a Política Nacional de Mobilidade Urbana, para priorizar dois tipos de transportes, os coletivos e os não motorizados, e a Lei no ${ }^{\circ} 13.724$ (Brasil, 2018), que cria o Programa Bicicleta Brasil (PBB), para incentivar o uso deste meio de transporte nas cidades, gerando melhores condições de mobilidade.

Concomitantemente, algumas soluções têm emergido como alternativas para nichos de mercado. Pode-se citar, nesse sentido, que o serviço de sistemas de bicicletas compartilhadas gradativamente se torna popular nas cidades brasileiras (Miñano \& Santos, 2015). Este modelo de compartilhamento tem se caracterizado como uma boa opção para o last mile (última milha), ao complementar o transporte público e fornecer uma alternativa barata e eficiente para deslocamentos curtos (Shaheen, Guzman, \& Zhang, 2010).

Destarte, observa-se a valorização da bicicleta inclusive durante o período de restrições sociais na pandemia de COVID-19 e seu uso tem sido sugerido, quando necessário, por não emitir gases poluentes, o que evita, assim, impactos no sistema respiratório, e por ser uma atividade física individual, que não gera aglomeração (Acioli et al., 2020). Apesar de não ser a solução definitiva para os problemas de mobilidade, o sistema se mostra eficaz para segmentos de mercado específicos. Contudo, de acordo com Soares (2015), há poucas pesquisas que identificam quantitativamente os usuários de bicicletas e sua segmentação.

Dessa maneira, delimitou-se o problema da pesquisa em responder qual a percepção das pessoas que se deslocam pela cidade de Nova Iguaçu e transitam por este município do Estado do Rio de Janeiro, com relação ao interesse em utilizar um Sistema de Compartilhamento de Bicicleta para mobilidade local. Para tanto, o trabalho teve como objetivo geral verificar o potencial de mercado para a implementação de um sistema de bicicletas compartilhadas na cidade de Nova Iguaçu, localizada na região da Baixada Fluminense, no Estado do Rio de Janeiro. A pesquisa tratou ainda dos seguintes objetivos específicos: a) identificar o segmento 
estudado; b) mapear os principais pontos de preferência do consumidor para uso do serviço nesta localidade; c) levantar as faixas de preço de acordo com os respondentes. O presente estudo trata-se, portanto, de uma pesquisa de mercado para análise desta demanda latente entre os respondentes.

\section{Referencial teórico}

\subsection{O Sistema de Bicicletas Compartilhadas}

Shaheen, Guzman e Zhang (2010) definem que os sistemas de bicicletas compartilhadas consistem na possibilidade de indivíduos usarem bicicletas quando necessário, sem arcar com os custos e as responsabilidades da sua propriedade, o que lhes proporciona um acesso de curto prazo e é uma forma ambientalmente amigável de transporte. As autoras afirmam a usabilidade dos sistemas de bicicletas compartilhadas para a última milha, a curta distância entre o destino inicial ou final e a estação de transporte público.

DeMaio e Gifford (2004) elencam alguns fatores que contribuem para o sucesso na implementação de sistemas de bicicletas compartilhadas, como: demanda do consumidor, infraestrutura cicloviária e segurança, lucratividade, e integração intermodal. Silveira (2010) também acrescenta benefícios ambientais, pois a bicicleta é o meio de transporte que apresenta o menor consumo de energia primário e é o mais adequado para curtas distâncias.

Diversos são os benefícios do sistema de bicicletas compartilhadas para a cidade, entre eles, a redução do tráfego de carro, o aumento da atratividade do transporte público e maior mobilidade ciclista. Os Sistemas de Bicicletas Compartilhadas (SBC) significam uma nova alternativa de transporte que torna possível novos deslocamentos e opções em relação aos modos tradicionais de transporte, o que produz externalidades positivas para as cidades e para os usuários desses sistemas (Miñano \& Santos, 2015). Além disso, possibilita a mais pessoas, mesmo sem que tenham uma bicicleta, o uso desse modo de transporte, o que faz com que a bicicleta possa retornar ao seu protagonismo antes do advento do automóvel nas cidades e volte a ser usada como um modo de transporte e não apenas de lazer (Melo, Marques, Almeida, \& Wanderley, 2015). O uso de bicicletas compartilhadas também está de acordo com a Lei nº. 12.587 (Brasil, 2012), no seu artigo $6^{\circ}$, pela priorização dos modos de transportes não motorizados sobre os motorizados; pela valorização dos serviços de transporte público coletivo sobre o transporte individual motorizado; pela integração entre os modos e serviços de transporte urbano; e pela mitigação dos custos ambientais, sociais e econômicos dos deslocamentos de pessoas e cargas na cidade. 
Vale ressaltar também a consonância entre o SBC e os Objetivos de Desenvolvimento Sustentável (ODS) da Agenda 2030. A Agenda 2030 é um plano de compromisso global para garantir que a população mundial possa desfrutar de paz e prosperidade, preservando o meio ambiente e diminuindo a pobreza (Nações Unidas do Brasil, 2015). Alguns ODS têm aderência com o SBC, como o ODS 9 - Indústria, Inovação e Infraestrutura, que trabalha com a criação de infraestruturas sustentáveis de qualidade, confiáveis e resilientes, para apoiar o desenvolvimento econômico e social, dando acesso e mobilidade à sociedade, principalmente aos grupos moradores de lugares mais periféricos. Já a ODS 11 - Cidades e Comunidades Sustentáveis discute a redução do impacto ambiental por meio de serviços básicos e acessíveis nas cidades, e trata de urbanização e da criação de espaços públicos seguros, inclusivos, acessíveis e verdes. O ODS 12 - Consumo e Produções Responsáveis concerne ao uso sustentável e eficiente de recursos naturais, à conscientização para o desenvolvimento sustentável e aos estilos de vida em harmonia com a natureza (Nações Unidas do Brasil, 2020).

SBC costumam estar presentes em áreas densas, com um alto número de conexões potenciais (DeMaio \& Gifford, 2004). Os autores também ressaltam que é comum a presença de estações de bicicletas compartilhadas próximas a estações do transporte público, o que melhora o acesso e a integração com elas. Shaheen, Guzman e Zhang (2010) acrescentam a usabilidade da bicicleta em conjunto com o transporte público, por ser o modo ideal para a "última milha", a curta distância entre as estações de transporte público e o destino inicial ou final, sendo a bicicleta um transporte complementar desse percurso. Miñano e Santos (2015), no entanto, relatam que a integração entre transporte público e bicicleta, no Brasil, ainda pode melhorar, pois, atualmente, apenas $10 \%$ das viagens de bicicleta são feitas assim. Dessa maneira, muitos consumidores de serviços de mobilidade urbana poderiam ter suas necessidades de deslocamento atendidas pela bicicleta se houvesse uma integração mais efetiva com o transporte público.

\subsection{A cultura e o consumo de bicicletas compartilhadas}

De acordo com Xavier (2011), a cultura tem relação com o desenvolvimento e a inserção da bicicleta nas políticas de mobilidade urbana brasileiras. De acordo com a autora, vive-se um contexto de cultura centrada no automóvel, que, apesar de não ser eficiente do ponto de vista coletivo, recebe uma grande quantidade de recursos da sociedade, portanto, a quebra do paradigma do automóvel na política de mobilidade urbana é uma questão social. Essa mudança de conceito pode garantir uma maior equidade no acesso ao espaço urbano, então é necessária 
a aceitação e a participação da população nesse processo de mudança. Ainda para Soares (2015), há uma necessidade cultural de se desmistificar, no Brasil, a bicicleta como veículo inferior e voltado, principalmente, para o lazer.

Kotler, Kartajaya e Setiawan (2017) demonstram que um processo de mudança já é uma realidade na sociedade, em que ocorre uma migração de valores sociais, antes vertical, exclusivo e individual, para uma atualidade mais horizontal, inclusiva e social. Segundo os autores, velhos padrões políticos, econômicos, sociais e religiosos da civilização estão sendo destruídos e substituídos por um conjunto mais horizontal e inclusivo de padrões sociais. A internet, ao proporcionar maior conectividade e transparência, tem grande peso na mudança de estrutura de poder, visto que "comunidades de consumidores se tornaram cada vez mais poderosas. Agora elas são mais ruidosas. Não têm medo das grandes empresas e marcas. Adoram compartilhar histórias, boas e ruins, sobre suas experiências de consumo" (Kotler, Kartajaya, \& Setiawan, 2017, p. 19).

Neste sentido, as bicicletas compartilhadas se destacam por esse fator de inclusão social, por possibilitarem uma opção barata e fácil de deslocamento e, assim, permitirem que pessoas de menor renda tenham maior acesso às oportunidades da cidade, o que oportuniza igualdade social no uso do espaço público (Miñano \& Santos, 2015).

Analisando a pesquisa Perfil do Ciclista, feita pela Transporte Ativo e LabMOB-UFRJ (2018), pode-se inferir que uma significativa parcela dos usuários de bicicletas o fazem por questões de saúde e recursos, visto que $38,4 \%$ as utilizam pela rapidez/praticidade; $28,6 \%$ pela saúde; $22,1 \%$ pelo custo; e 3,5\% por preocupação com o meio ambiente. A pesquisa mostra, portanto, que os fatores mais significativos de atração de ciclistas para o uso da bicicleta são a rapidez, a praticidade, a saúde e o custo. Arruda, Bandeira, Silva e Rebouças (2016) concluem que os valores pessoais dos consumidores de SBC influenciam em pequena escala o consumo colaborativo.

A visibilidade desse segmento da sociedade, apesar de crescente, não tem sido suficiente para pressionar o poder público para mudanças mais significativas. No entanto, entende-se que, apesar de todos os problemas que os movimentos sociais enfrentam em suas lutas diárias, ainda são eles os responsáveis pelas transformações coletivas e continuam a ser eles os fomentadores de uma consciência crítica (Xavier, 2011).

Já com relação às novas demandas que esses grupos trazem ao mercado, é relevante compreender que segmentos são grupos com necessidades e desejos diferenciados em um mercado (Kotler, 1999). Dentre os diferentes critérios de segmentação, observa-se que os SBC possuem segmentação geográfica, pois estão presentes em localidades específicas, como áreas 
centrais das cidades (DeMaio \& Gifford, 2004). Pode-se também dizer que são serviços com uma forte segmentação por ocasiões de uso, por atenderem a um público que tem a necessidade e o desejo de fazer uso da bicicleta como meio de transporte ou lazer, mas que não possui bicicleta ou lugar para estacionar (Miñano \& Santos, 2015).

Para Acioli et al. (2020), a bicicleta, acompanhando a variação das demandas nos últimos anos, traz também uma resposta contundente à necessidade de distanciamento e isolamento social dado o contexto de espalhamento do coronavírus ao redor do mundo. Os autores analisam a importância da bicicleta no contexto de pandemia, considerando a ciclomobilidade uma forma de transporte que atende às medidas sanitárias de contenção ao SARS-COV-2, por evitar aglomeração e ainda contribuir com a saúde física.

\subsection{Mobilidade Ativa como Instrumento para a Sustentabilidade nas Cidades}

O conceito de sustentabilidade está intrinsecamente ligado ao Triple Bottom Line, que, segundo Elkington (1994), atua em três grandes bases interligadas: a social, a econômica e a ambiental. Nesse sentido, observa-se que a mobilidade ativa se destaca por um baixo consumo energético e consequente baixa emissão de poluentes. Conforme apontado por Silveira (2010), a bicicleta é o modo de transporte com menor consumo primário de energia, sendo assim, é uma forma consideravelmente mais sustentável de transporte. A Comissão Europeia (2000) assinala que, dentre os modos de transporte urbano, o automóvel particular é o "campeão" em consumo de espaço, de energia primária e de emissão de poluentes.

Dessa forma, a atual conjuntura da Região Metropolitana do Estado do Rio de Janeiro, de crescimento do uso do automóvel particular e decrescimento dos usos de modos de transporte ativos, como a caminhada e a bicicleta, verificada pela Cia. Estadual de Engenharia de Transportes e Logística (Central, 2015), mostra-se insustentável. De acordo com o Ministério das Cidades (2005), as consequências desse modelo de mobilidade urbana são os custos sociais, a poluição atmosférica, o aumento dos acidentes de trânsito e do consumo de fontes nãorenováveis de energia.

Outros pesquisadores se debruçaram sobre o tema mobilidade, para que se compreenda como o SBC impacta a vida nas cidades. Saraiva, Ribeiro, Neckel, Silva e Lermen (2019) analisaram o entorno das estações de SBC da cidade de Passo Fundo-RS. A partir desse levantamento foi possível identificar regiões com diferentes potenciais no uso da bicicleta e concluiu-se que o entorno possui uma influência no tipo de demanda pelo sistema e que a presença de uma infraestrutura cicloviária é um dos fatores mais relevantes. Soares (2015), ao 
analisar se a bicicleta é, de fato, uma solução sustentável para a cidade de São Paulo-SP, afirma que há um aumento considerável do uso desse modo de transporte, entretanto, questiona se a bicicleta é apenas um modismo ou uma modalidade de transporte com uma importância cada vez maior.

Estudos realizados na cidade de São Paulo, elaborados pela Companhia de Engenharia de Tráfego (CET) e pela São Paulo Transportes S.A. (SPTrans) apontam que dos 23,4 milhões de viagens diárias na capital paulista, 130 mil são realizados com o uso das bicicletas e 5,1 milhões por automóveis. A pesquisa mostra ainda algumas das vantagens da bicicleta como meio de locomoção: baixo custo na aquisição e manutenção, agilidade nos deslocamentos para distâncias até cinco quilômetros, menor interferência no espaço público da cidade, contribuição à saúde do usuário e reduzido impacto ambiental (Soares, 2015, p. 21).

Enquanto os trabalhos anteriormente citados têm um foco na logística e em questões ambientais, Cruz, Cavalcante e Martins (2018) descrevem as transformações vividas na cidade de Fortaleza-CE em razão do incremento do uso da bicicleta. Os autores identificam o potencial da bicicleta para além do deslocamento, como atividade de lazer, saúde e oportunidades de viver e de se conectar com a cidade.

Leoni e Moscarelli (2018) fazem um panorama da evolução dos sistemas ao redor do mundo e dos instalados no país. Os SBC estão presentes desde 1965, quando o primeiro sistema foi instalado em Amsterdã, na Holanda. Desde então, diferentes gerações de sistemas de bicicletas públicas têm promovido uma série de avanços tecnológicos, o que garante uma maior cobertura da rede e da comodidade para o usuário.

\section{Matérias e métodos}

O presente trabalho trata-se de pesquisa descritiva quanto aos seus fins metodológicos. Vergara (2016) define que a pesquisa descritiva se destina a expor características de uma população ou um fenômeno, e também pode investigar interrelações entre as variáveis de determinado evento. Quanto aos seus meios, o trabalho se classifica como pesquisa de campo, com aplicação de questionário. Vergara (2016) explica que a pesquisa de campo se caracteriza como uma investigação empírica realizada onde ocorre um fato ou em lugares que possuam elementos que permitam a sua explicação. Dessa maneira, foi realizada a coleta de informações, a partir de questionários enviados por meios eletrônicos.

Os sujeitos selecionados para a pesquisa foram as pessoas que, independentemente da motivação ou do modo de transporte, deslocam-se para entrar ou sair do município de Nova Iguaçu-RJ e que também se movimentam pela cidade. Escolheu-se esse recorte para saber como se caracteriza um possível segmento que tenha interesse por um SBC. Segundo dados do Plano Diretor de Transporte Metropolitano (Central, 2015), 1,437 milhão de indivíduos se desloca 
frequentemente do/para o município. Esse valor total inclui pessoas que se movimentam de diferentes modos, a pé, de transporte coletivo e transporte individual.

O questionário para coleta de dados primários foi disponibilizado durante o mês de novembro de 2020, em grupos de redes sociais, no Facebook e no WhatsApp, de bairros da cidade, de universidades e referentes a locais de interesse, como centros comerciais de Nova Iguaçu-RJ. Esses grupos eram usados pelo público de interesse do estudo, ou seja, pessoas que se deslocam frequentemente no município. Para que os questionários chegassem até esses sujeitos, optou-se por trabalhar com seu envio por acessibilidade, conveniência e por meio do método bola de neve. O questionário estruturado com 23 perguntas fechadas foi criado no Google Forms e desenvolvido com base nos dados bibliográficos previamente estudados. O instrumento teve o propósito de descrever o perfil demográfico, psicográfico e comportamental do respondente, seus motivos e suas percepções a respeito da mobilidade na cidade de Nova Iguaçu-RJ, seu interesse no uso de bicicletas e de um SBC. O estilo de vida, o grau de satisfação com a forma de mobilidade atual, sua intenção e seus motivos para o uso de um SBC foram os principais parâmetros para avaliar qualitativamente a intenção de uso e interesse pelo serviço. Os resultados foram analisados de forma descritiva.

A pesquisa apresentou limitações, visto que o trabalho se delimitou apenas à intenção de uso e aos aspectos referentes ao interesse no mercado de bicicletas compartilhadas no município de Nova Iguaçu-RJ. Dessa maneira, elementos importantes, como políticas públicas de incentivo ao uso da bicicleta não foram contemplados neste artigo. Além disso, como se utilizou acessibilidade, conveniência e bola de neve para se chegar até os sujeitos da pesquisa, os resultados são representativos desse público, relacionados aos grupos das redes sociais escolhidas para divulgação.

\section{Análise dos resultados}

\subsection{Mobilidade na cidade de Nova Iguaçu-RJ}

Esta pesquisa tratou da mobilidade e da oportunidade para uso de bicicletas compartilhadas na cidade de Nova Iguaçu, localizada na Baixada Fluminense, quarto município mais populoso da Região Metropolitana do Estado do Rio de Janeiro. É um município que ocupa papel primordial nessa localidade por seu alto contingente populacional, bem como pelo total de viagens geradas de/para a cidade, aproximadamente, 1,437 milhão/dia, o que representa 6,4\% das viagens na região metropolitana (Central, 2015). 
As pessoas que entram e saem de Nova Iguaçu-RJ, independentemente da forma de mobilidade, são os sujeitos desta pesquisa, para quem foi direcionado o questionário para a coleta de dados. O levantamento realizado teve um total de 175 respostas, entretanto, foi feita uma pergunta de triagem, para saber se o respondente fazia parte, de fato, do público do interesse da pesquisa. Após a análise dessa questão, verificou-se que, dos 175 respondentes, 149 se deslocavam frequentemente para dentro do município ou para sair dele e passaram a compreender o quantitativo de sujeitos estudados na pesquisa.

Das 149 respostas a respeito das formas de deslocamento para entrar e sair do município, o transporte público aparece com a maior prevalência entre os pesquisados, com $81,21 \%$ deles declarando fazer seus deslocamentos por meio de transporte público $(50,34 \%$ usava apenas uma condução, e 30,87\% usava duas ou mais). O carro particular vem logo em seguida, com 11,41\% dos deslocamentos, seguido pelas corridas de aplicativo, com 2,68\% das respostas. Os deslocamentos por bicicleta também representaram uma pequena parcela de $2,68 \%$ dos respondentes. Apenas 0,67\% dos entrevistados declarou se locomover exclusivamente a pé para o município, como se pode observar no Gráfico 1, a seguir.

\section{Gráfico 1.}

Deslocamento para Entrar e Sair de Nova Iguaçu

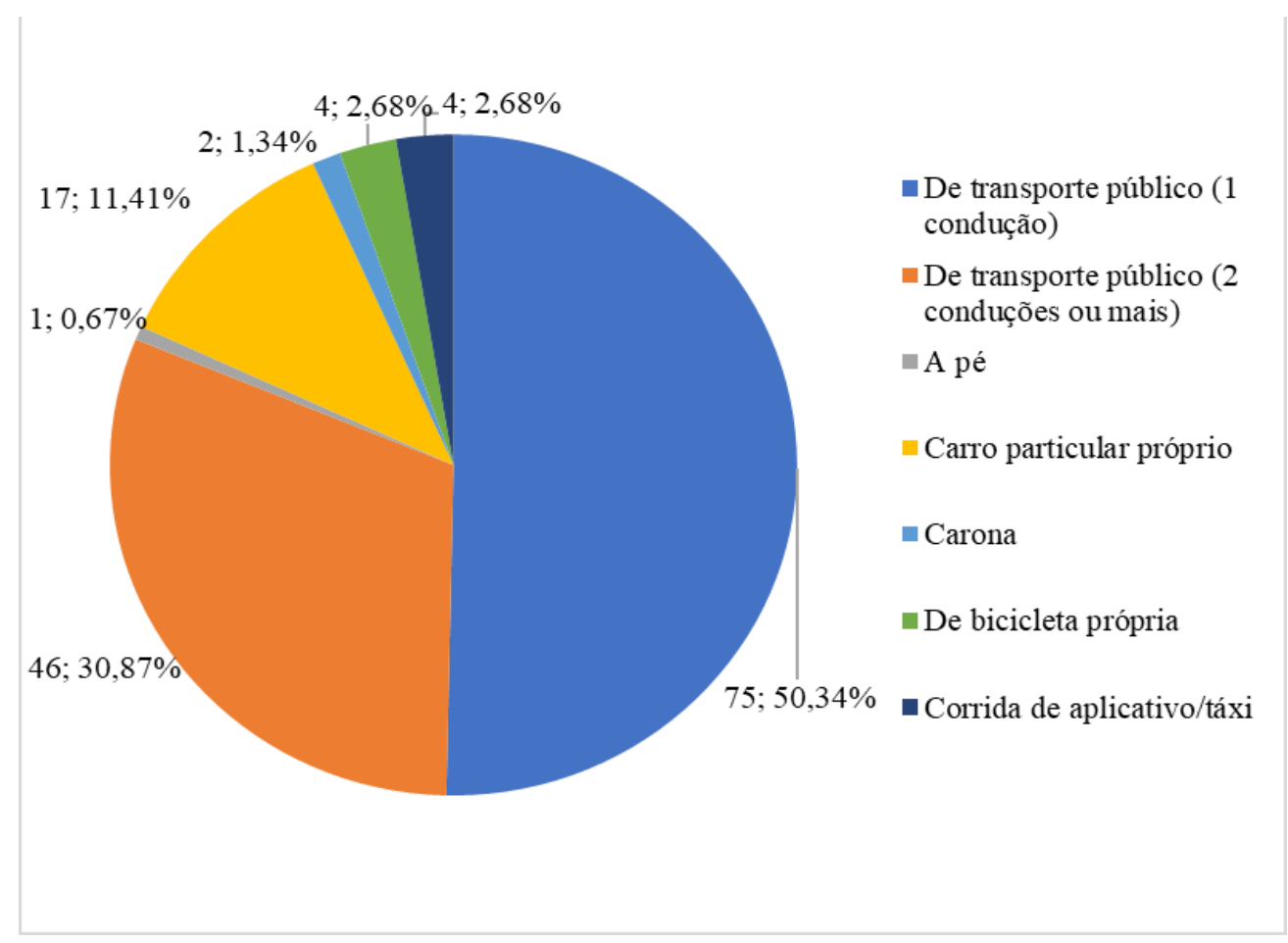

Fonte: Dados da Pesquisa, 2020. 
Quando perguntados sobre formas de locomoção dentro do município, 44,22\% se locomovem por transporte público, com uso de uma, duas ou mais conduções. Além disso, $22,45 \%$ dos entrevistados se deslocam a pé dentro do município. Não obstante, também pode se destacar o elevado percentual de deslocamentos de bicicleta (11,56\%). Carros particulares representam 10,88\% do total, enquanto corridas de aplicativos e táxis são 8,16\% do total. Além disso, 2,04\% dos entrevistados também declararam fazer uso de motocicleta. O Gráfico 2, a seguir, mostra de forma mais clara essa informação.

\section{Gráfico 2.}

Deslocamento no Município

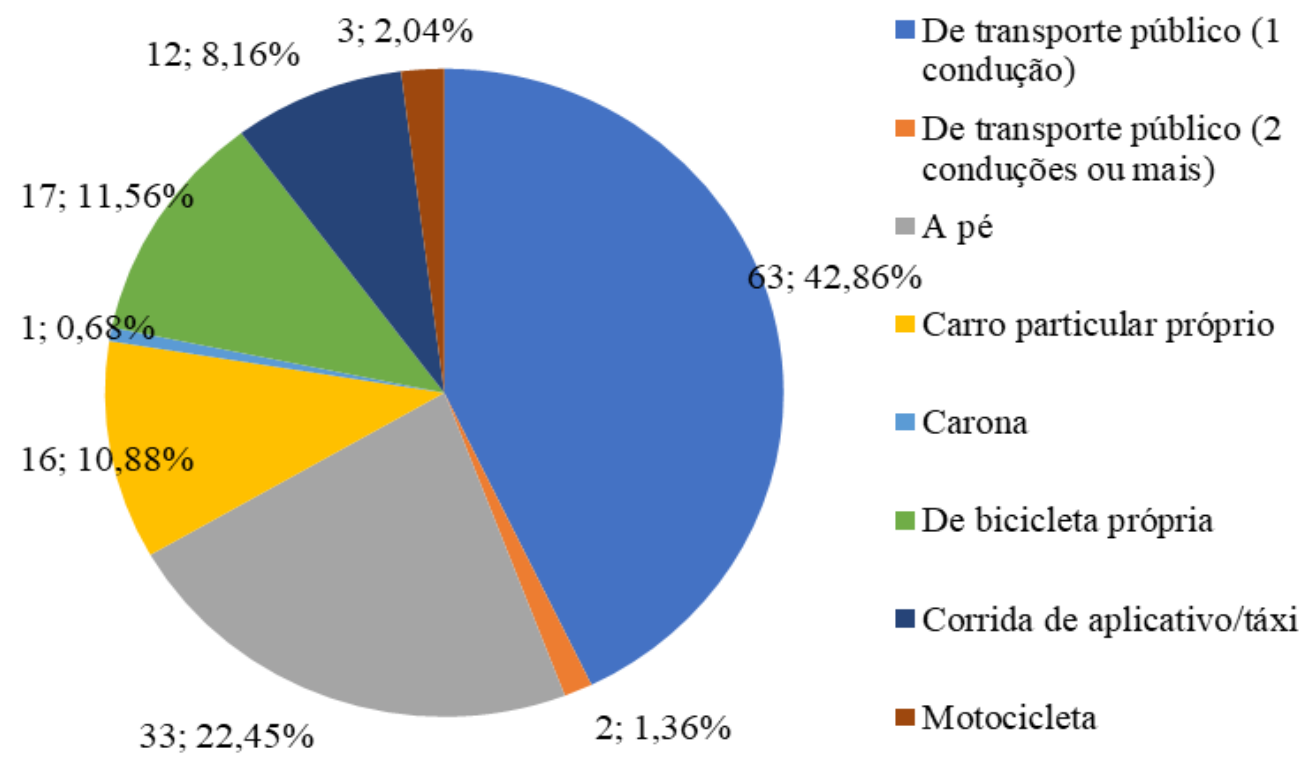

Fonte: Dados da Pesquisa, 2020.

Observa-se que, na Região Metropolitana do Rio de Janeiro (RMRJ), há, atualmente, uma prevalência de mobilidade por modos motorizados sobre os modos não-motorizados. Como afirma Xavier (2011), vive-se a cultura centrada no automóvel. Isso quer dizer que, apesar do disposto em lei, pela Política Nacional de Mobilidade Urbana (Brasil, 2012), que define os modos não-motorizados (a pé, bicicleta) como prioridade, na RMRJ, isso ainda não é uma realidade. A média de viagens não-motorizadas por habitante, por exemplo, recuou de 0,65 para 0,60, entre 2003 e 2012, o que representa um crescimento negativo de, em média, 0,88\% ao ano. Em compensação, o uso de transporte individual motorizado cresceu de 0,29 para 0,37 viagens por habitante, um crescimento médio de 2,87\% ao ano (Central, 2015). A Central (2015) descreve algumas razões para o declínio dos modos não-motorizados, como calçadas da 
baixa qualidade, sinalização deficiente e obstáculos de uso. Além disso, também é notável a influência do uso do solo, que demanda longos deslocamentos e inviabiliza deslocamentos por modos ativos.

A respeito da frequência de deslocamento, 34,90\% dos entrevistados responderam que se dirigem ao município até uma vez por semana. Em seguida, 29,53\% relataram se deslocar ao município de duas a três vezes por semana; $26,17 \%$ de quatro a cinco vezes por semana; e apenas $9,40 \%$ se deslocam todos os dias ao município. Essa informação está demonstrada no Gráfico 3.

\section{Gráfico 3.}

Frequência de Deslocamento

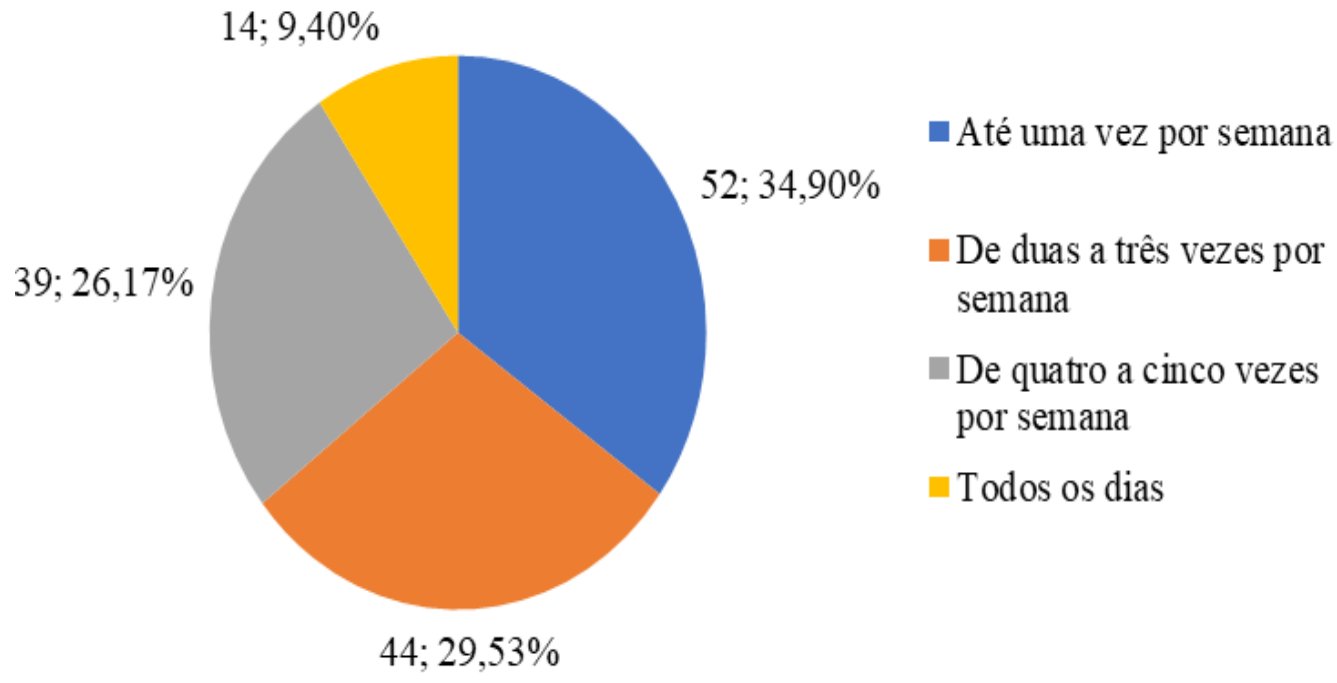

Fonte: Dados da Pesquisa, 2020.

\subsection{Grau de satisfação com o deslocamento pela cidade}

Quando questionados se estão satisfeitos com o deslocamento pela cidade, os respondentes demonstram insatisfação com o trânsito da cidade, visto que 74,5\% declararam estar descontentes com a qualidade do trânsito, por passarem muito tempo nele. Além disso, 20,81\% também destacaram a falta de segurança no trânsito para pedestres e ciclistas; $18,79 \%$ disseram que, apesar do trânsito ser satisfatório nos finais de semana, nos dias de semana, continua sendo problemático. Importante ressaltar que a rapidez e a segurança no trânsito já foram ressaltadas pela Transporte Ativo e LabMOB-UFRJ (2018) como determinantes para o uso da bicicleta. No Gráfico 4, a seguir, é possível verificar o grau de satisfação com a qualidade do trânsito de Nova Iguaçu-RJ. 


\section{Gráfico 4.}

Satisfação com o Trânsito

Depende, durante a semana não, mas no final de semana, sim

Não, sou pedestre/ciclista e não me sinto seguro em andar em meio aos carros

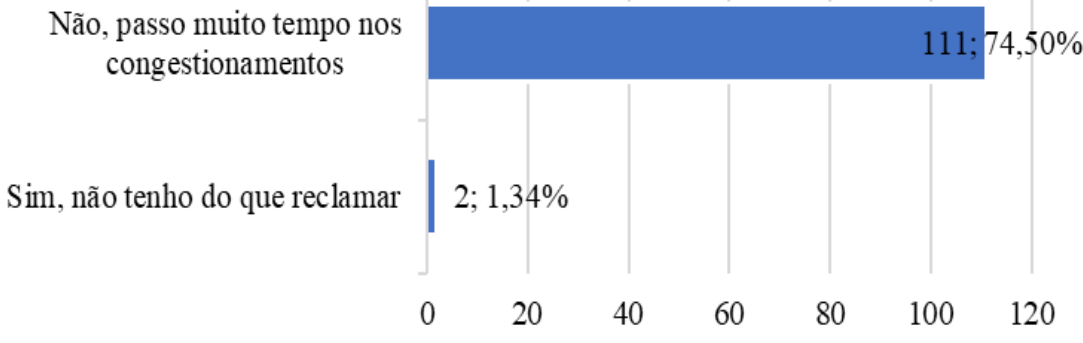

Fonte: Dados da Pesquisa, 2020.

Do total de entrevistados, $75,17 \%$ informaram estar insatisfeitos com o total de despesas diárias de deslocamento. Também é importante ressaltar que, conforme revelado pela pesquisa da Transporte Ativo e LabMOB-UFRJ (2018), o fator financeiro é relevante para 22,3\% dos ciclistas. Santos (2018) complementa ao trazer a ideia de que as bicicletas compartilhadas são uma inovação social que garante maior acessibilidade de transporte a mais pessoas. O Gráfico 5 traz informações a esse respeito.

\section{Gráfico 5.}

Grau de Satisfação com Despesas de Deslocamento

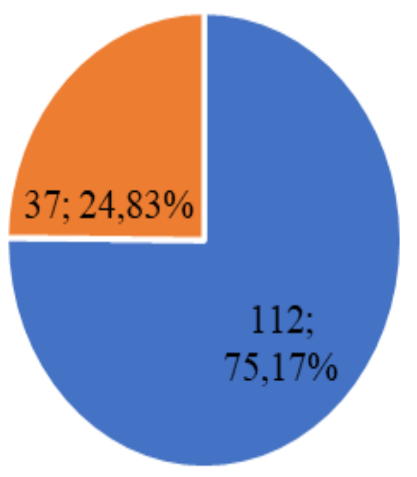

- Sim, não acho que gaste muito = Não, gasto demais e gostaria de reduzir

Fonte: Dados da Pesquisa, 2020. 


\subsection{Comportamento, estilo de vida, gostos e aversões}

Um dado revelado pela pesquisa e que está em consonância com aqueles verificados pelo LabMOB-UFRJ e Transporte Ativo (2018), foi o alto percentual de entrevistados que se declaram sedentários, porém com desejo de mudar essa condição: 58,39\% demonstram essa intenção, enquanto 38,26\% responderam que já fazem alguma atividade física. A atividade física também é uma das maiores vantagens do uso da bicicleta como meio de transporte (LabMOB-UFRJ \& Transporte Ativo, 2018; Acioli et al., 2020; Cruz, Cavalcante, \& Martins, 2018).

A respeito do uso da bicicleta, apenas 7,38\% declararam se deslocar de bicicleta para o centro de Nova Iguaçu-RJ. Dentre os motivos relacionados, destacam-se a falta de segurança no trânsito da cidade (para 53,91\% dos respondentes) e o fato de residirem muito longe do centro (para 42,97\% dos respondentes). Além disso, 29,69\% também reportaram dificuldades para estacionar a bicicleta no centro de Nova Iguaçu-RJ, assim como 26,56\% preferem usar outros modos de transporte. Um total de $21,88 \%$ assinalou ter medo da violência, o que mostra que esse também é um fator relevante para a mobilidade por bicicleta. Também se destacou o fato de $5,47 \%$ de respondentes terem declarado não se deslocar de bicicleta para o centro por não possuírem bicicleta. Esse fato está em consonância com Miñano e Santos (2015), que mostraram um aumento na compra de bicicletas próprias após a implementação de SBC nas cidades. Além disso, o fato de residir longe do centro pode ser um impeditivo para deslocamentos de bicicleta durante todo o trajeto, principalmente quando não há integração intermodal (Miñano \& Santos, 2015). No entanto, SBC se destacam por ser uma solução de alta eficácia para o last mile, a distância entre as estações de transporte público e o destino do passageiro (Shaheen, Guzman \& Zhang, 2015).

Dentre os que se deslocam de bicicleta até o centro, destaca-se a alta porcentagem de respondentes que não encontram estacionamento adequado para suas bicicletas $(93,33 \%)$, o que demonstra falta de infraestrutura para a armazenagem de bicicletas na região. Miñano e Santos (2015) também afirmam que essa é uma das maiores vantagens de SBC, por resolverem o problema de estacionamento da bicicleta para o usuário. O Gráfico 6, a seguir, ilustra as motivações para os respondentes não se deslocarem de bicicleta até o centro de Nova IguaçuRJ. 


\section{Gráfico 6.}

Por que não se Desloca por Bicicleta?

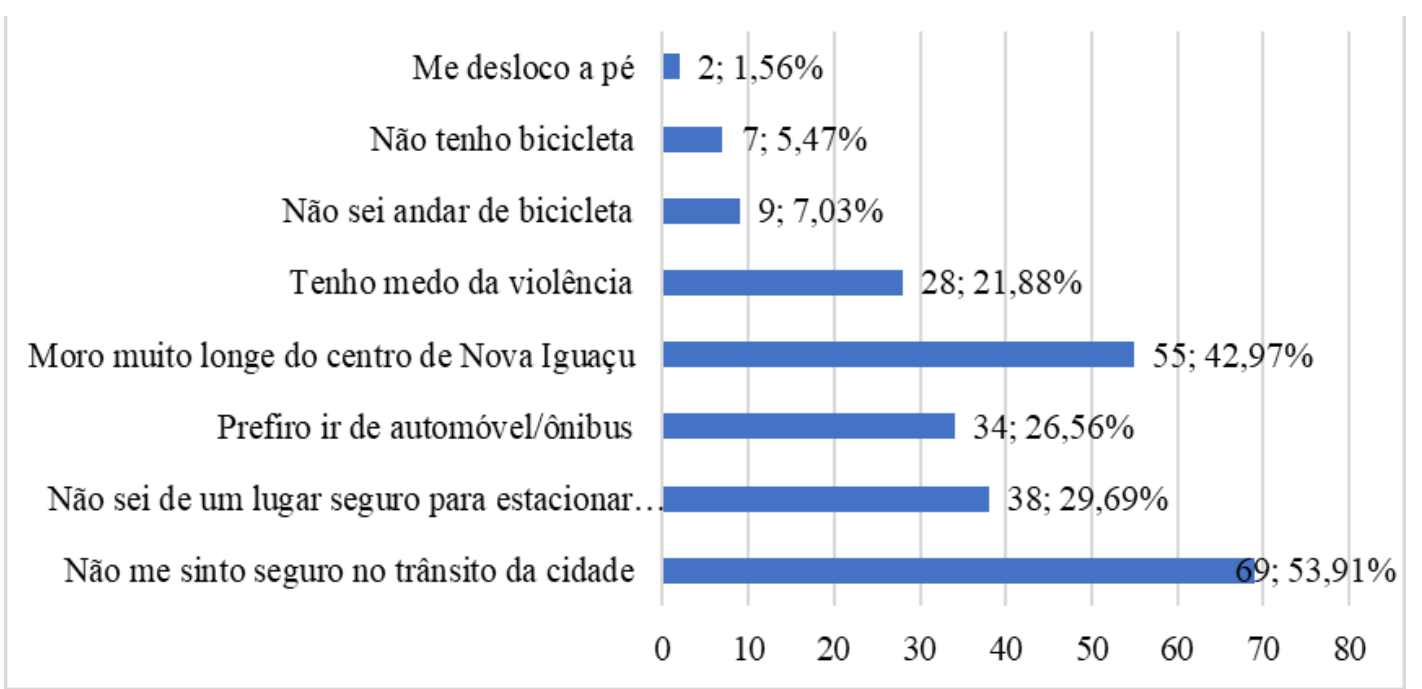

Fonte: Dados da Pesquisa, 2020.

Uma série de motivos pode explicar as escolhas de quem se desloca de bicicleta para o centro de Nova Iguaçu-RJ: 83,3\% dos entrevistados relataram maior rapidez no trânsito; 75\% falaram do amor à bicicleta; $75 \%$ o fazem para economizar dinheiro $(75 \%) ; 58,33 \%$ para ajudar o meio ambiente; e $33,33 \%$ por segurança.

Observa-se que, conforme Saraiva, Ribeiro, Neckel, Silva e Lermen (2019), o entorno das estações de SBC influencia no tipo de demanda pelo sistema, e a presença de uma infraestrutura cicloviária é um dos fatores mais relevantes. Dessa forma, observa-se, no Gráfico 6, a relevância de uma ciclovia para dar segurança ao usuário a fim de que se estimule o uso de bicicletas.

\section{Gráfico 7.}

Motivos para Andar de Bicicleta

Porque quero ajudar o meio ambiente

Porque me sinto mais seguro de bicicleta

Para economizar dinheiro Porque amo andar de bicicleta Porque acho lugares para guardar a bicicleta

Rapidez no trânsito

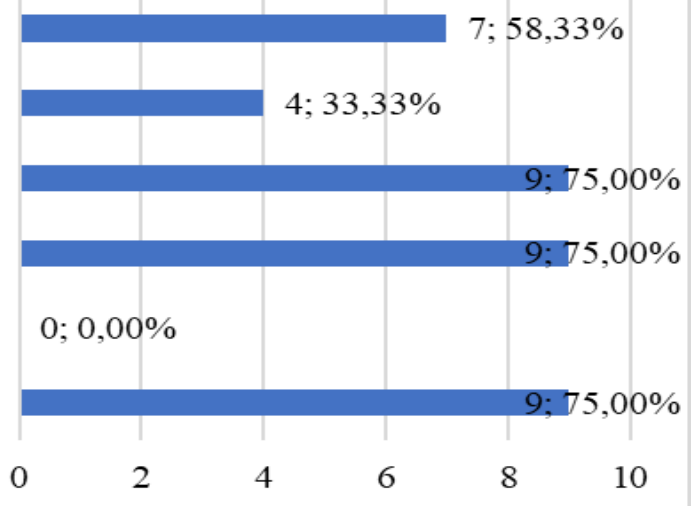

Fonte: Dados da Pesquisa, 2020. 


\subsection{Mapeamento do interesse pelo compartilhamento de bicicletas}

Foram verificados os destinos mais relevantes no centro de Nova Iguaçu-RJ. Em ordem de relevância, foram levantados: shopping a céu aberto (91 respostas); TopShopping (90); estação de trem (85); Shopping Nova Iguaçu (85); rodoviária de Nova Iguaçu (70); UFRRJ Campus Nova Iguaçu (63); Supermercados Guanabara (47); pontos de ônibus do Guanabara (38\%); ponto de ônibus da Leader/Via Light (36); Supermercados Extra (31); bares na Rua Coronel Bernardino de Melo (19); Supermercados Inter (14); Parque Natural Municipal (13); shopping automotivo na Avenida Nilo Peçanha (12); Vila Olímpica de Nova Iguaçu (9); Universidade Estácio - Campus Nova Iguaçu (8); Universidade Iguaçu (6); e FAETEC Campus Nova Iguaçu (3). Na Figura 1, a seguir, estão dispostos esses principais pontos.

\section{Figura 1.}

Mapa dos Pontos Relevantes
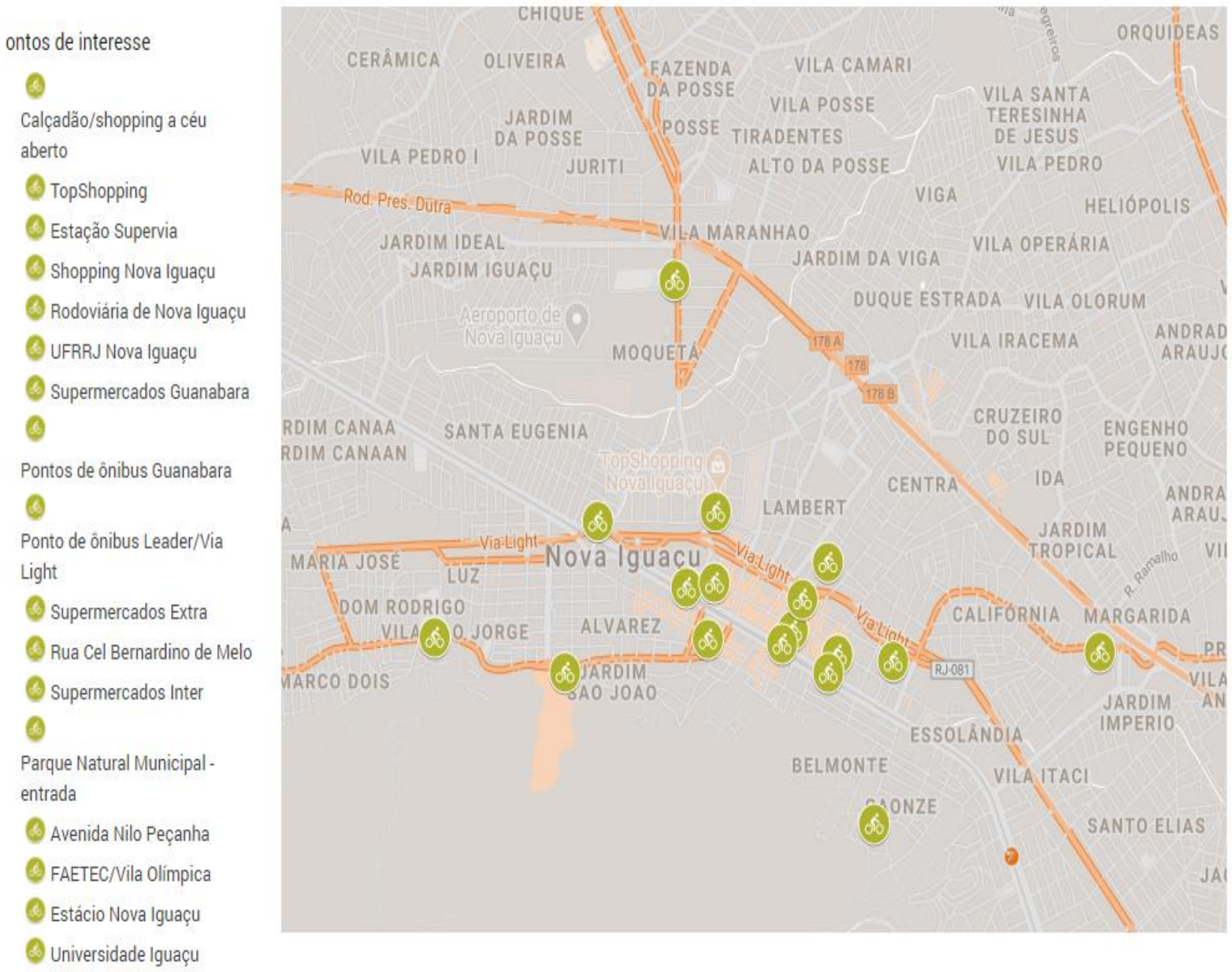

Fonte: Dados da Pesquisa (2020). 
Quanto à receptividade à implantação de um SBC, 62,42\% demonstraram que usariam esse sistema para circular pela cidade. Entre eles, 20,59\% pagariam até R\$5; 50\% pagariam entre $\mathrm{R} \$ 5$ e $\mathrm{R} \$ 15 ; 23,53 \%$ pagariam entre $\mathrm{R} \$ 15$ e $\mathrm{R} \$ 25$; e apenas 5,88\% pagariam $\mathrm{R} \$ 25$ ou mais. As formas de pagamento escolhidas seriam o cartão de débito (55,70\% dos respondentes), cartão de passagem $(50,34 \%)$, cartão de crédito $(48,99 \%)$, dinheiro em espécie $(39,60 \%)$, aplicativos de pagamento $(22,15 \%)$ e boleto bancário $(12,08 \%)$.

\section{Gráfico 8.}

Usaria Bicicletas Compartilhadas

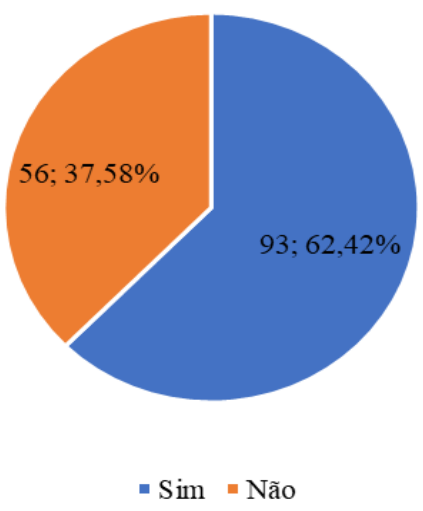

Fonte: Dados da Pesquisa, 2020.

Ainda a respeito de formas de pagamento, 65,10\% dos respondentes usariam RioCard+; 6,04\% usariam cartão GIRO; 5,37\% cartão Supervia; 4,03\% RioCard gratuidade; e 28,19\% não usariam cartão de transporte.

\section{Gráfico 9.}

Usaria Cartões de Transporte

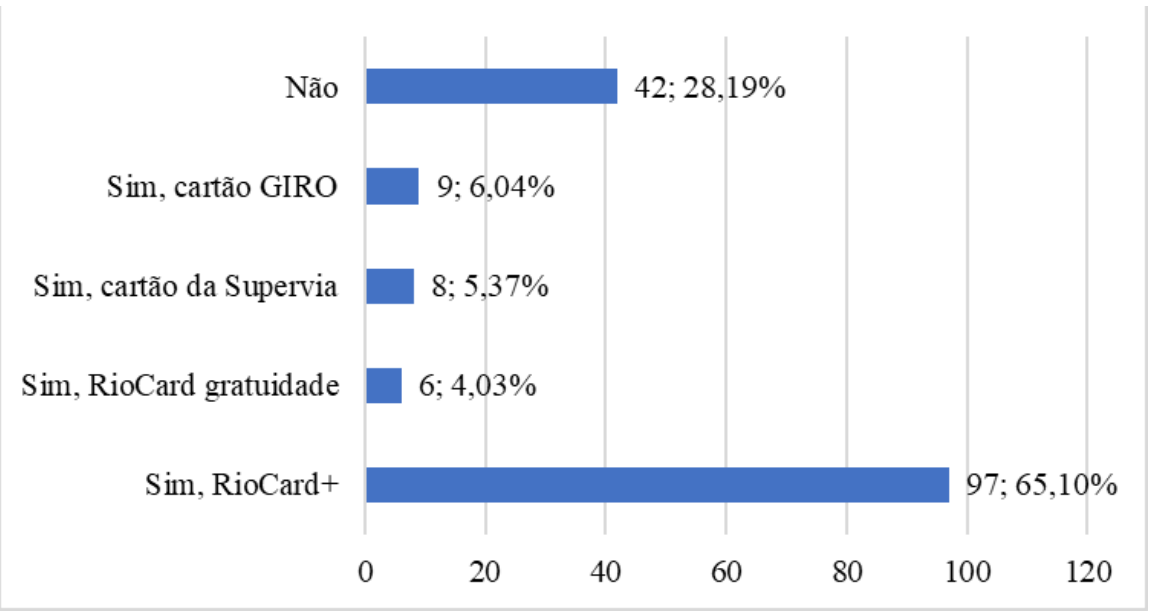

Fonte: Dados da Pesquisa, 2020. 
Observa-se que, quanto mais benefícios forem incorporados à mobilidade por bicicleta, maior será sua percepção de valor, o que impactará no preço do uso do serviço, que pode ser visto para além do transporte, como atividade de lazer, saúde e oportunidades de viver e se conectar com a cidade (Cruz, Cavalcante, \& Martins, 2018).

\section{Considerações finais}

As informações levantadas neste estudo indicam que há interesse dos sujeitos pesquisados na implantação de um SBC em Nova Iguaçu-RJ $(62,42 \%)$ e que a cidade pode ser considerada como um mercado potencial.

Os dados mostraram uma realidade favorável e em consonância com estudos da Pesquisa Perfil do Ciclista da Transporte Ativo e LabMOB-UFRJ (2018). Pode-se citar, por exemplo, o alto nível de descontentamento com o trânsito do município $(74,5 \%$ dos respondentes demonstraram insatisfação), o alto nível de descontentamento com os gastos com transporte (para 75,2\% dos respondentes) e a alta proporção de sedentários que desejam mudar seus hábitos (para 58,4\% dos entrevistados).

Além disso, também é importante ressaltar o potencial de atração de um SBC entre os próprios usuários de bicicleta, pois 93,3\% dos respondentes que afirmaram usar a bicicleta frequentemente relataram que possuem dificuldades de encontrar estacionamento seguro para elas. Além disso, destaca-se uma quantidade considerável (5\%) de entrevistados que relatou não possuir bicicleta, mesmo tendo interesse em pedalar, que poderia ser contemplada por um SBC.

A pesquisa também mostrou os maiores pontos de preferência dos respondentes. Foram levantados os principais focos de deslocamento e foi detectada uma diversidade de usos e geradores de deslocamentos, subdivididos entre comércio, escolas, universidades e demais equipamentos públicos. Os dados levantados pela pesquisa estão em consonância com aquilo apresentado por DeMaio e Gifford (2004) como fator determinante para o sucesso de um sistema de bicicletas alugadas: a densidade e o uso misto, típicos de áreas centrais, bem como a multiplicidade de conexões possíveis.

Foi verificado que $75,2 \%$ dos respondentes reportaram um desejo de diminuir suas despesas com transporte. A respeito da precificação para o consumidor, constatou-se que a maioria dos consumidores, $52,3 \%$, seria bem atendida por valores entre $\mathrm{R} \$ 5$ e $\mathrm{R} \$ 15$. Ressaltase, no entanto, que a precificação também envolve aspectos técnicos e operacionais de um SBC 
e cabem, portanto, estudos futuros para conhecer, de forma mais específica, os potenciais custos operacionais de um SBC na cidade.

Recomenda-se a extensão e o aprofundamento desta pesquisa em um segundo momento, levando em conta a necessidade de políticas públicas relacionadas à implementação de um SBC e a promoção da mobilidade ativa (DeMaio \& Gifford, 2004), especialmente no que se refere à segurança do trânsito, fator considerado problemático por 48,2\% dos respondentes. Apesar de o consumidor do município possuir necessidades coerentes com a implementação de um SBC, há uma série de fatores relacionados a políticas de governo que podem influenciar, positiva ou negativamente, na demanda por esse mercado.

Considera-se que há uma demanda latente pelo uso de bicicletas, visto que o segmento estudado percorre longas distâncias a pé dentro do município, entretanto, também se caracteriza pelo sedentarismo e pelo interesse por economia de gastos. Dessa forma, a motivação do uso da bicicleta compartilhada, entendida culturalmente como um suporte para além do transporte, um hábito saudável e de entretenimento, poderá agregar valor ao serviço.

\section{Referências}

Acioli, I. S. D., Ferreira, L. T., Melo, M. F., Andrade, N. P., Dias, C., \& Braga, I. Y. L. G. (2020) O Papel da Bicicleta Durante e Após a Pandemia do Novo Coronavírus. 34 Congresso de Pesquisa e Ensino em Transporte da ANPET 100\% Digital, 16 a 21 de novembro de 2020. Disponível: https://www.anpet.org.br/anais34/documentos/2020/Gest\%C3\%A3o\%20de\%20Transp ortes/Gest\%C3\%A3o\%20de\%20Transporte\%20I/3_241_AC.pdf

Arruda, H.R., Bandeira, E.L., Silva, A.L.L., \& Rebouças, S.M.D. P. (2016) Consumo Colaborativo e Valores Pessoais: O Caso da Bicicleta Compartilhada. Revista Brasileira de Marketing, 15(5).

Agenda 2030. (2020) A Agenda 2030 para o Desenvolvimento Sustentável. Disponível em: http://www.agenda2030.org.br/sobre/. Acesso em 10 de nov.

Brasil. Lei no. 12.587, de 3 de janeiro de 2012 (2012). Institui a Política Nacional de Mobilidade Urbana. Brasília, DF: Subchefia para Assuntos Jurídicos. Disponível: http://www.planalto.gov.br/ccivil_03/_Ato2011-2014/2012/Lei/L12587.htm

Brasil. Lei no. 13.724, de 4 de outubro de 2018 (2018). Institui o Programa Bicicleta Brasil (PBB) para incentivar o uso da bicicleta visando à melhoria das condições de mobilidade urbana. Brasília, DF: Subchefia para Assuntos Jurídicos. Disponível: http://www.planalto.gov.br/ccivil_03/_ato2015-2018/2018/lei/L13724.htm

CENTRAL - Cia. Estadual de Engenharia de Transportes e Logística. (2015). Plano Diretor de Transporte Metropolitano. Rio de Janeiro. 116p. 
Comissão Europeia (2000). Cidades para Bicicletas, Cidades de Futuro, Luxemburgo, Serviços das Publicações Oficiais das Comunidades Europeias.

Cruz, R. R. M. da, Cavalcante, S., \& Martins, J. C. de O. (2018). Mobilidade, Lazer e Sustentabilidade: A Bicicleta no Contexto Urbano da Cidade de Fortaleza. LICERE Revista do Programa de Pós-graduação Interdisciplinar em Estudos do Lazer, 21(1), 241-266. Disponível: https://periodicos.ufmg.br/index.php/licere/article/view/1778

DeMaio, P., \& Gifford, J. (2004). Will smart bikes succeed as public transportation in the United States? Journal of Public Transportation, 7(2), 1

Elkington, J. (1994). Towards the Sustainable Corporation: Win-Win-Win Business Strategies for Sustainable Development. California Management Review, 36, n. 2. 90-100.

Kotler, P. (1999) Marketing para o século XXI: como criar, conquistar e dominar mercados. $10^{\mathrm{a}}$ ed. São Paulo: Futura.

Kotler, P., Kartajaya, H., \& Setiawan, I. (2017). Marketing 4.0: do tradicional ao digital. Rio de Janeiro: Sextante.

Leoni, L. M. L., \& Moscarelli, F. da C. (2018) Bicicletas compartilhadas: Um panorama da evolução do sistema e dos programas instalados no país. XIV Semana de Extensão, Pesquisa e Pós-Graduação - SEPesq. Centro Universitário Ritter dos Reis.

Melo, R., Marques, J. R., Almeida, M. L., \& Wanderley, L. S. O. (2015) Bicicleta compartilhada em uma abordagem prática: material, competência e significados. In: Anais do Encontro Internacional sobre Gestão Empresarial e Meio Ambiente, São Paulo.

Miñano, M. P., \& Santos, A. (2015). Contribuição dos serviços de bicicleta compartilhada na mobilidade sustentável no Brasil. In: CONGRESSO BRASILEIRO DE TRANSPORTE E TRÂNSITO ANTP, 20., Anais. Santos, 2015.

Ministério das Cidades, (2005). A mobilidade urbana no planejamento da cidade, Cartilha, Secretaria Nacional de Transporte e da Mobilidade Urbana.

Nações Unidas no Brasil - ONU BR. (2020) A Agenda 2030. Disponível em: https://nacoesunidas.org/pos2015/agenda2030

Santos, A. S. L. (2018). Inovação social no campo da mobilidade urbana: um estudo com as bicicletas compartilhadas. Dissertação (Mestrado) - Programa de Pós-graduação em Administração e Controladoria, Universidade Federal do Ceará, Fortaleza, 2018.

Saraiva, P. P., Ribeiro, L. A., Neckel, A., Silva, J. L., \& Lermen, R. T. (2019). Avaliação da influência do entorno no uso das estações de bicicletas compartilhadas. urbe. Revista Brasileira de Gestão Urbana, 11, e20180105. https://doi.org/10.1590/21753369.011.001.AO1. Disponível: https://www.scielo.br/j/urbe/a/wMPBwzbD7pP5XT36KrYjrjk/?lang=pt\&format=pdf 
Shaheen, S. A., Guzman, S., \& Zhang, H (2010): Bikesharing in Europe, the Americas, and Asia. Transportation Research Record: Journal of the Transportation Research Boar, 159-16.

Silva, F. N. (2013). Mobilidade urbana: os desafios do futuro. Cad. Metrop, 15(30).

Silveira, M. O. (2010). Mobilidade sustentável: a bicicleta como um meio de transporte integrado. 168 f. Dissertação (Mestrado) - Programa de Pós-graduação em Engenharia de Transportes, Universidade Federal do Rio de Janeiro, Rio de Janeiro.

Soares, R. D. G. (2015). Bicicleta e mobilidade urbana: modismo ou solução sustentável para o transporte na cidade de São Paulo. Universidade de São Paulo Escola de Comunicações e Artes Centro de Estudos Latino-Americanos Sobre Cultura e Comunicação. Novembro de 2015. Disponível: https://paineira.usp.br/celacc/sites/default/files/media/tcc/versao_final_pdft.pdf

Transporte Ativo, \& Labmob UFRJ (2018). Pesquisa perfil do ciclista. Rio de Janeiro.

Vergara, S. C (2016). Projetos e Relatórios de Pesquisa em Administração. 16ª ed. São Paulo: Atlas.

Xavier, G. N. A. (2011). O desenvolvimento e a inserção da bicicleta na política de mobilidade urbana brasileira. Tese (Doutorado) - Programa de Pós-Graduação Interdisciplinar em Ciências Humanas, Universidade Federal de Santa Catarina. Disponível: https://repositorio.ufsc.br/handle/123456789/95554?show=full 